\title{
Species Composition and Burden of Small Intestinal Parasitic Helminth in Goats and Sheep Slaughtered at Bishoftu Elfora Export Abattoir (Ethiopia)
}

\section{Getu Hurisa \\ Lama Yimer \\ Morka Amante (D)}

Wollega University, School of Veterinary Medicine, Nekemte, Ethiopia
Correspondence: Lama Yimer Wollega University, School of Veterinary Medicine, Nekemte, Ethiopia Tel +251917081237

Email lemayimer@gmail.com
Purpose: Although helminthiasis have been recognized as health constraints of small ruminants, there was no study conducted to reveal their types and burden in goats and sheep slaughtered at Bishoftu, Ethiopia. Hence, this study is aimed to evaluate the current status of helminth parasites and estimate its burden in study animals.

Methods: The study was carried out from November 2016 to April 2017 to identify the species and also to estimate the burden of small intestinal parasitic helminth in goats and sheep using a standard worm recovery procedure. The study animals were 230 goats and sheep slaughtered at Bishoftu Elfora export abattoir during the study period.

Results: The study revealed that the overall infection rate was $83.5 \%$. Among 105 samples taken from sheep, $87.6 \%$ were positive, whereas 100 (80\%) of 125 examined samples from goats were positive for helminth parasites. There was no statistically significant difference $(p>0.05)$ between the species. However, age and animal origin considered as a risk factor indicated statistically significant differences $(p<0.05)$. In sheep, the prevalence of Trichostrongylus colubriformis, Bunostomum trigonocephalum, and Moniezia expansa was 69 (46.9\%), 34 (43.6\%), and 51 (52.6\%), respectively, while the prevalence of Trichostrongylus colubriformis, Bunostomum trigonocephalum, and Moniezia expansa in goats was 78 (53.1\%), 44 (56.4\%), and 46 (47.4\%), respectively.

Conclusion: This study revealed a high infection with parasitic helminths. Thus, effective control and prevention methods are necessary to minimize their effects on animals as well as the economy.

Keywords: Bishoftu, burden, goat, helminths, nematode, parasite and sheep

\section{Introduction}

Ethiopia is one of the countries with the largest number of small ruminants in Africa. The most recent estimate of small ruminant population is 23.6 million sheep and 23.3 million goats. ${ }^{1}$ Goats and sheep provide about $46 \%$ of the national meat consumption and $58 \%$ of production of hides and skins. They have more benefits such as lower feeding costs, faster turnaround, ease of use and reasonable size at slaughter compared to large ruminants. ${ }^{2,3}$

Despite the large small ruminant's population of Ethiopia, the economic benefits remain minimal due to diseases, management constraints, reproductive efficiency, etc. $^{4-7}$ Parasitic diseases are a major health constraint for goat and sheep production. $^{8}$ In Ethiopia, intestinal helminths resulted in decline in production and economic losses. They also have a major impact on rates of mortality and morbidity. ${ }^{9}$ 
Helminths in particular nematodes is of great concern in many agro ecological areas of Africa, but the outcome is greatest in Saharan Africa broadly and in Ethiopia in particular because of the availability of a variety of agroecological factors and parasite species. ${ }^{10}$ Trichostrongylus colubriformis and Bunostomum trigonocephalum are the most common small intestinal worms of sheep and goats in most of the world, including the tropics, causing significant production losses. ${ }^{11,12}$

Even though the driving factors of helminth parasitism in ruminants are various and often interactive, the majority of cases have one of the following main reasons: alteration in host susceptibility, an increment in number of infectious stages on pasture, entry of susceptible populations into an infected environment, entry of infections into environment and inefficient elimination of the parasite from host animals due to development of anthelmintic resistance, mismanagement techniques, or incorrect anthelmintic usage. ${ }^{13}$

Approximately $95 \%$ of goats and sheep are infected with helminths, with Trichostrongylus and Haemonchus being the primary species involved. Several authors have reported production losses due to mortality and reduced weight gain. ${ }^{14}$ Studies on ruminants from different regions of Ethiopia have shown a prevalence of $47.67 \%$ to $84.1 \%{ }^{15,16}$ Although several studies on helminth of the small intestine have been carried out in different areas of Ethiopia, no study has been carried out in the current study area.

Therefore, the aim of this study was:

- To identify as well as quantify small intestinal helminth parasites in goats and sheep slaughtered at ELFORA export abattoir (Bishoftu, Ethiopia).

\section{Methods}

\section{Study Animals}

Sheep $(\mathrm{n}=105)$ and goats $(\mathrm{n}=125)$ slaughtered at ELFORA export abattoir were examined. The animals brought to the abattoir were from Borana, Somale, and Jinka. Borana is located around $600 \mathrm{~km}$ south of Addis Ababa. The climate is semi-arid with an annual mean daily temperature from $19^{\circ} \mathrm{C}$ to $24^{\circ} \mathrm{C}$ with moderate seasonal differences. ${ }^{17}$ Study animals were also from Jinka, South Omo zone of Ethiopia. This area has a temperature range between $15.7^{\circ} \mathrm{C}$ and $38^{\circ} \mathrm{C} .{ }^{18}$ Another source of the slaughtered animals was Somali, which is found in the Eastern part of Ethiopia at $9^{\circ} 20 \mathrm{~N}$. It is one of the semiarid parts of the country. ${ }^{19}$

\section{Study Design}

The study design used was cross-sectional. A total of 105 and 125 respective small intestines of sheep and goats were carefully collected from ELFORA export abattoir during the study period.

\section{Sample Collection and Laboratory Analysis Worm Recovery}

Laboratory work was conducted at Addis Ababa University College of Veterinary Medicine (Parasitology laboratory). A classical method ${ }^{20,21}$ was employed for small intestine worm recovery, counting, and species identification.

\section{Species Identification}

Preserved worms were poured into petri dishes for examination using stereo microscope Identification of the species and determination of the degree of infection were done using keys developed by various researchers (Hansen and Perry) and MAFF.

\section{Data Management and Analysis}

All collected data were entered into an Excel sheet and later analyzed using SPPS 20 version. Descriptive statistics were computed and $\chi^{2}$ values were used to test the association.

\section{Results}

A total of 230 goats and sheep (125 goats and 105 sheep) were examined and 192 (83.5\%) were infected with at least one helminth parasite (Table 1). The number of infected sheep and goats was $92(87.6 \%)$ and 100 (80\%), respectively. Generally, Trichostrongylus colubriformis, Bunostomum trigonocephalum, and Moniezia expansa in small ruminant were 147 (63.9\%), 78 $(33.9 \%)$, and 97 (42.2\%), respectively. The prevalence of Trichostrongylus colubriformis, Bunostomum trigonocephalum, and Moniezia expansa in sheep was 69 (46.9\%), $34(43.6 \%)$, and 51 (52.6\%) respectively, while the prevalence of Trichostrongylus colubriformis, Bunostomum trigonocephalum, and Moniezia expansa in goats was $78(53.1 \%), 44(56.4 \%)$, and 46 (47.4\%) respectively. Table 1 indicate intestinal helminth parasites identified in sheep and goats.

Fifteen $(12 \%)$ goats were found to be infected with all the three parasites identified, while $53(42.4 \%)$ and 42 $(33.6 \%)$ were found to be infected with two and one parasite 
Table I Helminth Parasites in Sheep and Goats

\begin{tabular}{|l|c|c|c|c|c|c|c|}
\hline \multirow{2}{*}{ Species } & \multirow{2}{*}{ Amount (N) } & \multicolumn{2}{|c|}{ T. colubriformis } & \multicolumn{2}{|c|}{ B. trigonocephalum } & \multicolumn{2}{c|}{ M. expansa } \\
\cline { 3 - 8 } & & Positive & $\%$ & Positive & $\%$ & Positive & 5 \\
\hline Sheep & 105 & 69 & 65.7 & 34 & 43.6 & 52.6 & 47.4 \\
Goat & 125 & 78 & 61.2 & 44 & 56.4 & 97 & 42.2 \\
Total & 230 & 147 & 63.9 & 78 & 33.9 & 97 \\
\hline
\end{tabular}

species, respectively. Of these, 78 (74.3\%) were harboring nematode parasitic worms. Twenty (19\%) sheep were infected with all the three species, while $23(21.9 \%)$ were infected with two helminths . Significant differences were not found in all species of intestinal helminths and body condition categories (Table 2). As indicated in Table 2, the prevalence of ovine and caprine helminths based on origin indicates a significant difference.

\section{Parasitic Burden}

Out of 105 sheep infected with T. colubriformis, 15 (14.3\%) were light infection, whereas 49 (46.6\%) and $3(2.85 \%)$ were moderately and heavil infected, respectively. Similarly, 18 (14.4\%) goats had light infection with $T$. colubriformis, while only $63(50.4 \%)$ and 2 (1.6\%) had moderate and heavy infection, respectively. Of those animals harboring B.trigonocephalum, 22 (56.4\%) sheep and $17(43.6 \%)$ goats had a light degree of infection, $24(36.9 \%)$ sheep and $41(63 \%)$ goats had a moderate degree and no goats were found with dense infection (Table 3).
Table 3 Degree of Helminths Infection in Sheep and Goats

\begin{tabular}{|c|c|c|c|c|c|c|}
\hline \multirow[t]{2}{*}{ Degree } & \multicolumn{2}{|c|}{$\begin{array}{l}\text { Ovine } \\
(n=\mid 05)\end{array}$} & \multicolumn{2}{|c|}{$\begin{array}{l}\text { Caprine } \\
(n=\mid 25)\end{array}$} & \multicolumn{2}{|c|}{$\begin{array}{l}\text { Sheep } \\
\text { +Goat }\end{array}$} \\
\hline & Tr. c & Bu. $\mathbf{t}$ & Tr. c & Bu. $t$ & Tr. c & Br. $t$ \\
\hline Light & 15 & 22 & 18 & 17 & 33 & 39 \\
\hline Moderate & 49 & 24 & 63 & 41 & 112 & 65 \\
\hline Heavy & 3 & 3 & 2 & 0 & 5 & 3 \\
\hline Negative & 38 & 56 & 42 & 67 & 80 & 123 \\
\hline Total $(n=230)$ & 67 & 49 & 83 & 58 & 150 & 107 \\
\hline
\end{tabular}

Abbreviations: Tr. c, Trichostrongylus colubriformis; Bu. t, Bunostomum trigonocephalum.

\section{Discussion}

In this study an overall prevalence of $83.5 \%$ has been found. The recorded prevalence is lower in comparison with the $92 \%$ found in sheep and goats ${ }^{10}$ in Ogaden region and $100 \%$ in sheep ${ }^{22}$ from Hawassa. The higher prevalence recorded in the current study during the period from November 2016 to April 2017 might be attributed to unfavorable temperature and rainfall for development of free living stages of helminths on pasture during the study period. ${ }^{10}$

Table 2 Frequency of Helminths in Sheep and Goats

\begin{tabular}{|c|c|c|c|c|c|c|}
\hline \multirow[t]{2}{*}{ Factors } & \multicolumn{2}{|c|}{ Sheep $(N=105)$} & \multicolumn{2}{|c|}{ Goat $(N=\mid 25)$} & \multirow[t]{2}{*}{$x^{2}$} & \multirow[t]{2}{*}{$p$-value } \\
\hline & No Examined & Positive (\%) & No Examined & Positive (\%) & & \\
\hline \multicolumn{7}{|l|}{ Age } \\
\hline 6 month-I year & 52 & 45 (42.8\%) & 52 & 43 (34.4\%) & 4.175 & 0.0324 \\
\hline I year & 36 & 34 (32.4\%) & 43 & $33(26.4 \%)$ & & \\
\hline $\mathrm{I}-2$ years & 17 & $13(12.4 \%)$ & 30 & $24(19.2 \%)$ & & \\
\hline \multicolumn{7}{|l|}{ Body condition } \\
\hline Good & 48 & 4I (39\%) & 61 & 53 (42.4\%) & 2.496 & 0.287 \\
\hline Medium & 57 & $51(48.6 \%)$ & 64 & 47 (37.6\%) & & \\
\hline \multicolumn{7}{|l|}{ Origin } \\
\hline Jinka & 15 & $10(9.5 \%)$ & 66 & $60(48 \%)$ & 5.252 & 0.042 \\
\hline Borana & 51 & 45 (42.9\%) & 29 & $23(18.4 \%)$ & & \\
\hline Somale & 39 & 37 (35.2\%) & 30 & $17(13.6 \%)$ & & \\
\hline Total & 105 & 92 (87.6\%) & 125 & $100(80 \%)$ & & \\
\hline
\end{tabular}


Between species the prevalence was $80 \%$ in goats and $87.6 \%$ in sheep. There was a higher prevalence of small intestinal helminths both in sheep (87.6\%) and goats (80\%). This is low when compared to the $97.4 \%$ (sheep) and $94.4 \%$ (goat) prevalence recorded in Hawassa town. The difference might be attributed to the effect of year and site on helminth prevalence. ${ }^{23}$

There was no significant difference in prevalence of small intestinal helminth parasites between goats and sheep. Even though the prevalence of $M$. expansa and $B$. Trigonocephalum tended to be high in sheep, it failed to be statistically significant. In contradiction to our observation, Bitew et $\mathrm{al}^{24}$ reported a higher prevalence of intestinal nematodes in sheep than in goats from the same study area. Kumsa et $\mathrm{al}^{25}$ also reported a higher prevalence of Moniezia in sheep than in goats from central Ethiopia through coprological examination.

The prevalence of T. colubriformis in sheep $(65.7 \%)$ and goats $(61.1 \%)$ was lower compared to the $83.5 \%$ and $77.5 \%$ prevalence reported for sheep and goats respectively, by Aragaw and Gebreegziabher ${ }^{23}$ from Hawassa town. It was much higher when compared within the prevalence of $14.7 \%$ and $24.4 \%$ recorded for T. colubriformis in sheep and goats, respectively, in the Sudan $^{26}$ and $16 \%$ for sheep in Iran. ${ }^{27}$ The prevalence of B. trigonocephalum in sheep (43.6\%) and goats (56.4\%) was lower compared to $50.9 \%$ for sheep but higher when compared the $38 \%$ prevalence reported for sheep and goats by Aragaw and Gebreegziabher ${ }^{23}$ from Hawassa town. Much lower prevalences of $70 \%$ and $60 \%$ were recorded for T. colubriformis in sheep and goats, respectively, in the same area. ${ }^{22}$ The prevalence of $M$. expansa in sheep $(52.6 \%)$ and goats $(47.4 \%)$ was in agreement compared to the $69 \%$ and $54.9 \%$ prevalence reported for sheep and goats, respectively, by Aragaw and Gebreegziabher ${ }^{23}$ from Hawassa town. There was a much higher prevalence when compared within $13 \%$ and $29.2 \%$ recorded for T. colubriformis in sheep and goats, respectively, in the same area. ${ }^{22}$

The degree of infection of T. colubriformis between species was $63.8 \%$ and $68 \%$ in sheep and goats, respectively. There was agreement when compared within $64.6 \%$ and $67.6 \%$ in sheep and goats in studies by Aragaw and Gebreegziabher ${ }^{23}$ and Bitew et al. ${ }^{24}$ at hawassa town. The degree infection of $B$. trigonocephalum between species was $46.7 \%$ and $46.4 \%$ in sheep and goats, respectively. It is in disagreement when compared to the degree of infection $(0 \%)$ in both sheep and goats study at hawassa town by Aragaw and Gebreegziabher ${ }^{23}$ and Bitew et al. ${ }^{24}$ in which the majority of $T$. colubriformis infections were light and all of the B. trigonocephalum infections were moderate.

A significant difference $(p>0.05)$ was not observed in the prevalence of the parasite on different age groups. Sheep and goats at the age of 6 months -1 year had higher prevalence than those aged 1-2 years (Table 2). The study found that the prevalence decreased as age increased. This is in agreement with the research done by Bitew et al. ${ }^{24}$ Though the reasons behind age resistance are not well known, it might be because of the development of acquired immunity and immune-competence that increase as age increases due to the high rate of exposure to parasitic infestations. Young animals are highly susceptible due to immunological immaturity and immunological unresponsiveness. ${ }^{13,14}$

\section{Conclusion}

The post-mortem examination revealed the presence of small intestine helminths infection in the study areas. The findings of this study indicated that helminths of sheep and goats is prevalent in the area. $T$. colubriformis, $B$ trigonocephalum, and $M$. expansa were identified from the small intestine of goats and sheep. Species and age were considered, indicating sheep were more infected than goats. Six months up to 1 year old animals were more infected than greater than 1 year. Thus, appropriate control methods such as strategic vaccination with more detailed investigation is necessary to minimize further losses associated with helminth infections.

\section{Abbreviations}

Bu. T, Bunostomum trigonocephalum; CACC Central Agricultural Census Commission; MAFF, Ministry of Agriculture, Fisheries and Food; M.E, Moniezia expansa; SOZAO, South Omo Zone Agricultural Office; SNNP, South Nation Nationality and People; Tr. C, Trichostrongylus Colubriformis.

\section{Data Sharing Statement}

All data collected, then analyzed for this study are incorporated in this article.

\section{Ethics Consideration}

The best practice guidelines for Sample collection and transport (OIE Manual) were followed. Permission to visit the study sites and to collect the samples were conducted as to the purpose of the study. 


\section{Acknowledgments}

The authors would like to thank ELFORA abattoir as well as the college of veterinary medicine of Addis Ababa University for their cooperation during the study. All authors participated equally from the conception to realization of the study.

\section{Funding}

No specific funding is associated with this work.

\section{Disclosure}

The authors declare no conflicts of interest for this work.

\section{References}

1. CSA. Report on Livestock and Livestock Characteristics. Addis Ababa, Ethiopia: CSA; 2012.

2. Abegaz S. Genetic Evaluation of Production, Reproduction and Survival in a Flock of Ethiopian Horro Sheep [PhD thesis]. South Africa: University of the Free State; 2002.

3. Donkin E. Sustainable livestock development in Africa: how do we help Africa to feed itself? SA Anim Sci. 2005;6. Available from: http://www.sasas.co.za/Popular/Popular.html.

4. Mukasa-Mugerwa E, Lahlou-Kassi A, Anindo D, et al. Between and within breed variation in lamb survival and the risk factors associated with major causes of mortality in indigenous Horro and Menz sheep in Ethiopia. Small Rumin Res. 2000;37:112. doi:10.1016/S09214488(99)00152-2

5. Tibbo M, Woldemeskel M, Gopilo A. An outbreak of respiratory disease complex in sheep in central Ethiopia. Trop Anim Health Prod. 2001;33:355-365. doi:10.1023/A:1010565905004

6. Kassa H. Livestock and Livelihood Security in the Harare Highlands of Ethiopia: Implications for Research and Development. [Doctoral thesis]. Uppsala, Sweden: Swedish University of Agricultural Sciences; 2003.

7. Tibbo M, Mukasa-Mugerwa E, Woldemeskel M, Rege J. Risk factors for mortality associated with respiratory disease among menz and Horro sheep in Ethiopia. Veterin J. 2003;165:276-287. doi:10.1016/ S1090-0233(02)00184-3

8. Mulcahy G, Sandra O, Sheila D, Dalton J. Helminths at mucosal barriers-interaction with the immune system. Adv Drug Deliv Rev. 2004;56:853868. doi:10.1016/j.addr.2003.10.033

9. Scala A, Spezzigu A, Soriolo A, et al.The gastro-intestinal nematodes as reducing fertility factor in Sarda breed sheep: field experiences. 19th International congress of Mediterranean Federation of Health and production of Ruminants; May 25-28; Belgrade, Serbia. 2011:340-342.

10. Kumsa B, Wossene A. Abomasal nematodes of small ruminants of Ogaden region, eastern Ethiopia: prevalence, worm burden and species composition. Rev Med Vet. 2006;157:27-32.
11. Taylor A, Coop L, Wall R. Veterinary Parasitology. 3rd ed. UK: Blackwell; 2007:158.

12. Abunna F, Kumsa B, Megersa B, Regassa A, Debela E. Abomasal nematodes: prevalence in small ruminants slaughtered at Bishoftu town, Ethiopia. J Veterin Med. 2009;7:1-6.

13. Urquhart G, Armour J, Duncan J, Dunn A, Jennings F. Veterinary Parasitology. 2nd ed. United Kingdom: Blackwell Science; 1996:307.

14. Blackie S. A review of the epidemiology of gastrointestinal nematode infections in sheep and goats in Ghana. J Agricult Sci. 2014;4:109.

15. Regassa F, Sori T, Dhuguma R, Kiros Y. Epidemiology of GIT parasites of ruminants in Western Oromia, Ethiopia. Intern $J$ Appl Res Vet Med. 2006;4(1):36-44.

16. Dagnachew S, Asmare A, Wudu T. Epidemiology of gastrointestinal helminthiasis of small ruminants in selected sites of North Gondar zone, Northwest Ethiopia. Ethiop Veterin J. 2011;15:57-68.

17. Dugassa H, Duguma R, Gebru G. Prevalence of some parasitic helminths and causation of organ condemnation among small ruminants originated from some selected locations of Ethiopia. Acta Parasitologica Globalis. 2014;5(1):33-47.

18. South Omo Zone Agricultural Office. Annual Report on Zonal Livestock Production. Jinka, Ethiopia: South Omo Zone Agricultural Office; 2006.

19. CACC. (Central Agricultural Census Commission): Ethiopian Central Agricultural Sample Enumeration, 2001/02, Statistical Report on Livestock and Farm Implements, Addis Ababa, Ethiopia. CACC; 2003.

20. Jacquie P, Cabaret J, Cheikh D, Thiam E. Identification of Haemonchus species in domestic ruminant based on morphometrics of spicules. Vet Parasitol. 1997;83:82-86.

21. Hansen J, Perry B. The Epidemiology and Control of Helminth Parasites of Ruminants. A Hand Book. Nairobi, Kenya: International Laboratory for Research on Animal Disease (ILRAD); 1994:171.

22. Kumsa B, Abeju N. Comparative efficacy of albendazole, tetramisole and ivermectin against gastrointestinal nematodes in naturally infected sheep in Hawassa, southern Ethiopia. Rev Med Vet. 2008;159:593-598.

23. Aragaw K, Gebreegziabher K. Small intestinal helminth parasites in slaughtered sheep and goats in Hawassa, Southern Ethiopia Hawassa University, School of Veterinary Medicine. Afri J Basic Appl Sci. 2014;6(2):25-29.

24. Bitew M, Amde Y, Belachew K. Abomasal and small intestinal nematodes of small ruminants slaughtered in different restaurants in Hawassa. Vet Res. 2011;4(2):39-44.

25. Kumsa B, Tadesse T, Sori T, Duguma R, Hussen A. Helminths of sheep and goats in central Oromia (Ethiopia) during the dry season. $J$ Anim Veterin Adv. 2011;10(14):1845-1849. doi:10.3923/ javaa.2011.1845.1849

26. Almalaik AHA, Bashar AE, Abakar AD. Prevalence and dynamics of some gastrointestinal parasites of sheep and goats in Tulus area based on post-mortem examination. Asian J Anim Veterin Adv. 2008;3 (6):390-399. doi:10.3923/ajava.2008.390.399

27. Naem S, Gorgani N. Gastrointestinal parasitic infection of slaughtered sheep (Zel breed) in Fereidoonkenar city, Iran. Veterin Res Forum. 2011;2(4):238-241.
Veterinary Medicine: Research and Reports is an international, peerreviewed, open access journal publishing original research, case reports, editorials, reviews and commentaries on all areas of veterinary medicine. The manuscript management system is completely online and includes a very quick and fair peer-review system. Visit http://www.dovepress.com/testimonials.php to read real quotes from published authors. 